\title{
Box-Shape Cervical Expansive Laminoplasty: Clinical and Radiological Outcomes
}

\author{
Hae Gi Park', Ho Yeol Zhang ${ }^{2}$, Sang Hoon Lee ${ }^{2}$ \\ ${ }^{I}$ Department of Neurosurgery, Spine and Spinal Cord Institute, Yonsei University College of Medicine, Seoul, \\ ${ }^{2}$ Department of Neurosurgery, National Health Insurance Corporation Ilsan Hospital, Goyang, Korea
}

Objective: Box-shape cervical expansive laminoplasty is a procedure that utilizes a Miniplate ${ }^{\circledR}$ or Maxpacer ${ }^{\circledR}$ to achieve maximal canal expansion. This method is expected to show much larger canal expansion and good clinical outcome. So we investigated the clinical and radiological outcome of Box-shape cervical expansive laminoplasty.

Methods: Between June 2008 and July 2013, we performed cervical expansive laminoplasty in 87 and 48 patients using the Box-shape cervical expansive laminoplasty, respectively. We analyzed the clinical results of these operations using the Japanese Orthopedic Association (JOA) scoring system and by assessing the position of intralaminar screws with postoperative computed tomography (CT) at POD-6 months.

Results: A total of 48 patients with ossification of the posterior longitudinal ligament (OPLL) (36 pts), cervical spondylotic myelopathy (CSM) (12 pts) were enrolled. Overall JOA scores improved from 11.49 to 14.22 at POD-6 months (OPLL: 11.32 ->14.3; CSM: 12-->14). Postoperative CT scans were performed in 39 patients at 177 levels for a total of 354 screws. The malpositioning rate of intralaminar screws was $3.4 \%$ and hardware-related neurologic complications did not occur. Conclusion: Box-shape cervical expansive laminoplasty creates maximal spinal canal expansion and leads to improved cervical myelopathy. The use of intralaminar screws to fix the remodeled lamina-facet does not represent a significant difficulty.

Key Words: Open door laminoplasty $\cdot$ Double door laminoplasty $\cdot$ Intralaminar screw $\cdot$ Spinal canal area $\cdot$ Box-shape laminoplasty

\section{INTRODUCTION}

Degenerative cervical spondylosis, herniated cervical discs, and ossification of the posterior longitudinal ligament (OPLL) can result in chronic compression of the spinal cord. Surgical treatment for this condition requires an anterior or posterior approach. Posterior approaches to decompression, such as laminectomy and laminoplasty, are typically indicated for cervical myelopathy ${ }^{3,6,7,10,16,19)}$. Cervical laminoplasty has gradually become an established intervention for compression. Cervical ex-

\footnotetext{
- Received: June 19, 2014 - Revised: August 20, 2014

- Accepted: August 25, 2014

Corresponding Author: Sang Hoon Lee, MD, PhD

Department of Neurosurgery, National Health Insurance Corporation Ilsan Hospital, 1232 Baekseok-dong, Isandong-gu, Goyang 410-719, Korea

Tel: +82-31-900-3478, Fax: +82-31-900-0588

E-mail: drm-neurg@hanmail.net

®This is an Open Access article distributed under the terms of the Creative Commons Attribution Non-Commercial License (http://creativecommons.org/ licenses/by-nc/3.0/) which permits unrestricted non-commercial use, distribution, and reproduction in any medium, provided the original work is properly cited.
}

pansive laminoplasty was originally carried out using spinous processes as spacers. Since development of classic open-door laminoplasty with the use of sutures, the procedure has been modified to reduce complications such as restenosis, axial symptoms, and segmental motor paralysis ${ }^{1,12-14,20)}$.

Various modifications to expansive laminoplasty have been developed and clinical outcomes are typically satisfactory in patients with cervical spondylotic myelopathy (CSM). In fact, one of the most popular modifications is a bilateral hinge-type laminoplasty procedure called the double-door laminoplasty. Development of surgical implants for expansive laminoplasty has resulted in surgeons using various kinds of lamina spacers.

Previously, we introduced a new type of modified expansive double-door laminoplasty that utilizes a titanium miniplate system for an Box-shape cervical expansive laminoplasty ${ }^{14}$. This method showed much higher canal expansion rate than that of other cervical spacers such as hydroxyapatite (HA) (Apaceram ${ }^{\mathbb{B}}$ ) and Centerpiece ${ }^{\circledR 8,9,14)}$ (Fig. 1). So this new method was expected to show good clinical outcome but it was not studied up to date.

In this study, we analyzed clinical and radiological outcomes of Box-shape cervical expansive laminoplasty. 


\section{MATERIALS AND METHODS}

\section{Study Population}

Between June 2008 and July 2013, a total of 87 patients with OPLL and CSM underwent laminoplasty at our institute with Box-shape cervical expansive laminoplasty (60 pts), Apaceram ${ }^{\circledR}$ $(1 \mathrm{pt})$, centerpiece ${ }^{\circledR}(20 \mathrm{pts})$. All patients presented myelopathy in a physical exam and cord compression was observed by MRI.

A total of 48 patients (OPLL (36 ts), CSM(12 pts)) that underwent Box-shape cervical expansive laminoplasty with Miniplate ${ }^{\circledR}$ or Maxpacer ${ }^{\circledR}$ were enrolled to this study. Male patients were more common than females $(\mathrm{M}: \mathrm{F}=35: 13)$ and the average age was $62.83(\max 81, \min 30)$ (Table 1$)$.

\section{Surgical Techniques}

A French-door (double-door) laminoplasty was used in all cases discussed. Horizontal amputation of the spinous processes was performed and bilateral lamina exposure was carried out. Midline laminotomy was subsequently achieved with a drill and lateral outer cortical bone drilling was performed to facilitate elevation. When performing lateral outer cortical bone drilling, the surgeon must find the lamina-facet junction, which is a landmark for drilling. It is important to drill medially to the facet joint to have adequate spinal canal area. Because

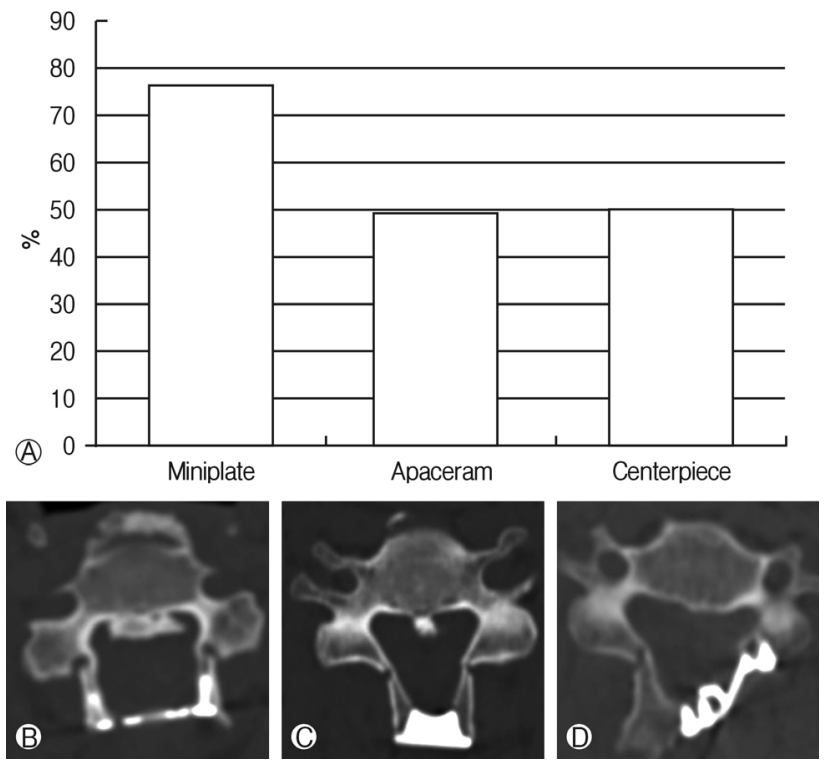

Fig. 1. (A) Canal expansion rate for surgeries performed with Boxshape cervical expansive laminoplasty, Apacerum ${ }^{\circledR}$, and Centerpeice $^{\circledR}$. CT axial image of the (B) Box-shape cervical expansive laminoplasty, (C) Apacerum ${ }^{\circledR}$, and (D) Centerpeice ${ }^{\circledR}$. a narrow drilling space can induce lamina fracture during elevation, adequate space is important to avoid fracture. After drilling, the ligament flavum was split centrally and each lamina and ligamentum flavum was opened bilaterally until the lamina stood straight. After proper positioning of the lamina, miniplates were applied to the space between both lamina. Intra-laminar drilling was performed for miniplate screw fixation. A miniplate is typically fixed with an $8-\mathrm{mm} \mathrm{screw}^{14)}$.

\section{Assessment of Clinical and Radiological Outcome}

Clinical outcomes of patients who received Box-shape cervical expansive laminoplasty were assessed at postoperative day (POD)-6 months using the JOA scoring system, performed by a single observer in all 48 patients. Clinical outcomes were compared to patients with OPLL (36 pts), CSM (12 pts) before and after surgery.

Postoperative CT scans were performed in 39 patients at 177 levels for a total of 354 screws to investigate the position of intralaminar screws.

\section{RESULTS}

\section{Clinical Outcomes}

For patients given the Box-shape cervical expansive laminoplasty, the total average JOA score improved from 11.49 to 14.22 by POD- 6 months. In the 36 patients with OPL, scores improved from 11.32 to 14.3 . In the 12 patients with CSM, scores improved from 12 to 14 (Table 2). Most patients' JOA

Table 1. Patient demographics who received laminoplasty with the Box-shape cervical expansive laminoplasty

\begin{tabular}{ll}
\hline \hline Number of patients & 48 \\
Sex (M:F) & $35: 13$ \\
Average age & $62.83($ Max =81, Min=30) \\
Number of levels & 218 \\
Number of diseases & 48 \\
OPLL & 36 \\
CSM & 12 \\
\hline
\end{tabular}

Table 2. JOA scores for a patient who received laminoplasty with Box-shape cervical expansive laminoplasty

\begin{tabular}{lcc}
\hline \hline & $\begin{array}{c}\text { JOA score } \\
\text { at pre-op }\end{array}$ & $\begin{array}{c}\text { JOA score } \\
\text { at POD-6 months }\end{array}$ \\
\hline Total $(n=48)$ & 11.49 & 14.22 \\
$\operatorname{OPLL}(n=36)$ & 11.32 & 14.3 \\
$\operatorname{CSM}(n=12)$ & 12.0 & 14.0 \\
\hline
\end{tabular}


scores improved and there were none with JOA scores that decreased (Fig. 2). Only one patient suffered from temporary C5 palsy at 5 to 7 days POD.

\section{Radiological Outcomes}

Of the 48 patients that received the Box-shape cervical expansive laminoplasty, postoperative CT scans were performed in 39 patients at 177 levels for a total of 354 screws. The total malposition rate of intralaminar screws was only $3.4 \%$ (12 out of 354). The rates of medial invasion (Fig. 3), lateral invasion (Fig. 4), center to medial invasion, center to lateral invasion, and pulling out were $4 \%, 2 \%, 0 \%, 4 \%$, and $1 \%$, respectively (Table 3). But, hardware-related neurological com plications did not occur in any of the cases.

\section{DISCUSSION}

Cervical laminoplasty is widely used to treat cervical myelopathy with OPLL or spondylosis. There have been many reports regarding satisfactory surgical outcomes using this procedure $^{1,6,7,10,12,16,19)}$. Double-door laminoplasty was originally devised by Kurokawa in Japan. This method achieves expansion of the spinal canal and preservation of the posterior structures for stability ${ }^{11,13,14,18-20)}$.

The relationship between degree of spinal canal expansion and clinical outcomes was not known and current techniques for canal expansion are not sufficient, ${ }^{5,9}$. However, maintaining spinal canal expansion is critical. So we developed the Box-shape cervical expansive laminoplasty for use with the

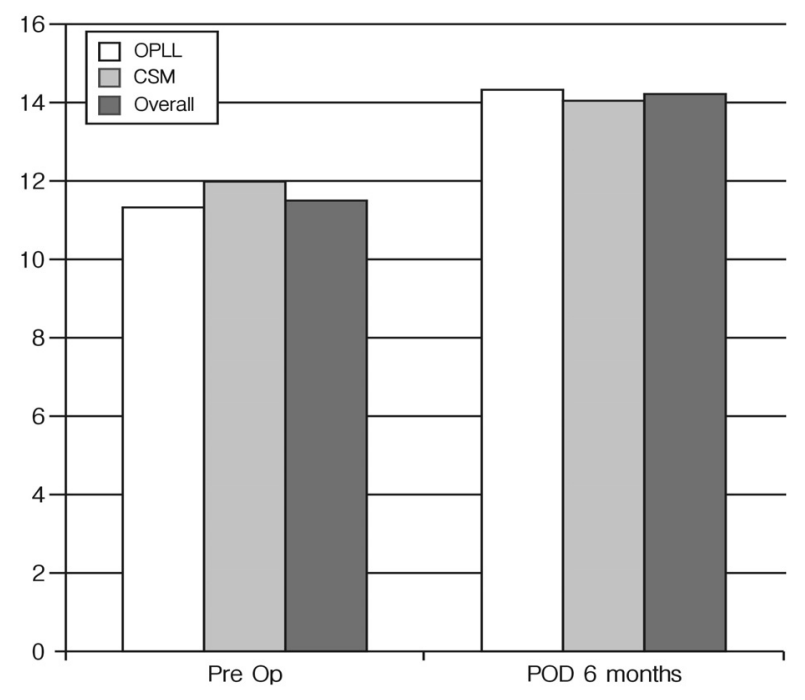

Fig. 2. JOA scores are given for the patient who received Boxshape cervical expansive laminoplasty.
Miniplate ${ }^{\circledR}$ or Maxpacer ${ }^{\circledR}$. The Box-shape cervical expansive laminoplasty allowed for maximal expansion of the spinal canal, and neurologic deterioration caused by restenosis or hinge reclosure did not occur ${ }^{14)}$.

Cervical laminoplasty using plating systems has been previously performed. Edmund Frank et al. reported a technique using titanium miniplates that permitted adequate decompression of the cervical spinal cord and bilateral cervical nerve roots. They showed successful reconstruction of an enlarged rigid spinal canal. Deutsch and Harel et al. showed successful laminoplasty using a Ti-Mesh LP miniplate system without complications in five patients. Park and Andrew E et al. reported performing laminoplasty using a novel titanium system that provided secure laminar fixation, thus minimizing the risk of canal restenosis, better preserving motion and decreasing axial neck pain ${ }^{2,4,17)}$.

In this study, we investigated clinical outcomes associated with our procedure. We show that those who received Boxshape cervical expansive laminoplasty had an average JOA score increase from 11.49 to 14.22 at POD-6 months. None of the patients displayed decreased JOA scores and none developed neurologic deficits. One patient, however, suffered from C5 palsy at PODs 5 to 7, but they completely recovered by POD-6 months. Although excessive opening of the spinal canal
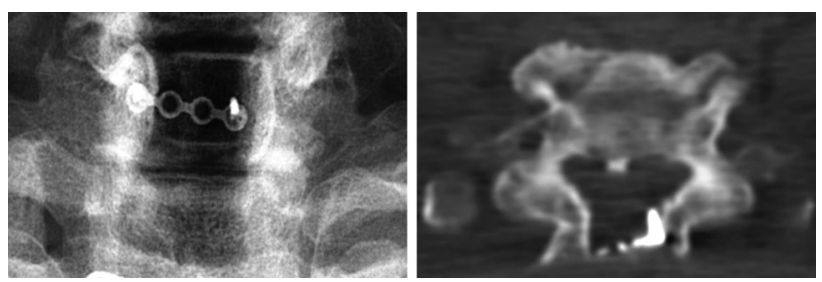

Fig. 3. A medially malpositioned intralaminar screw is shown.
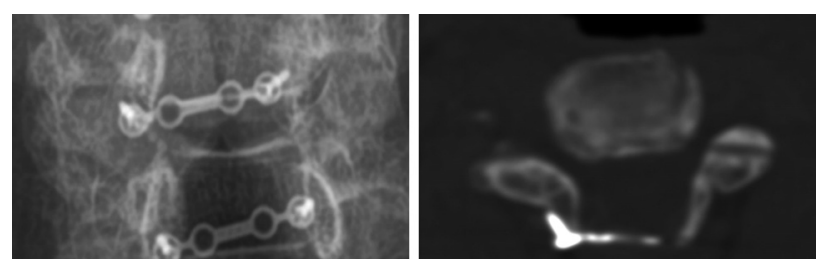

Fig. 4. A laterally malpositioned intralaminar screw is shown.

Table 3. Malpositioned intralaminar screws

\begin{tabular}{lc}
\hline \hline Total number of malpositioned screws & $12(3.4 \%)$ \\
\hline Medial invasion & 4 \\
Lateral position & 2 \\
Center to medial & 0 \\
Center to lateral & 4 \\
Pull out & 1 \\
Spinous process & 1 \\
\hline
\end{tabular}


results in risk of nerve root kinking and epidural scar tissue $^{21,22)}$, the major finding of this study is that maximal expansion of the spinal canal leads to improvements in JOA scores of patients with severe OPLL or CSM with narrowed canals. This result demonstrates the clinical efficacy of Box-shape cervical expansive laminoplasty.

The defining characteristic of this operation is the use of intralaminar screws to create maximal standing at each lamina. However, the double-door laminoplasty to create maximal lamina standing is a difficult technique and insertion of intralaminar screws at the proper position can be tedious. Proper positioning of the intralaminar screw is important for holding the remodeled lamina-miniplate.

To determine whether screws were inserted in the proper intralaminar position, we reviewed postoperative CT scans of the surgical methods at POD-6 months. Of the 39 patients, scanned at 177 levels in 354 screws, the malpositioning rate of intralaminar screws was only $3.4 \%$. No hardware-related complications occurred in patients after POD- 6 months and there were only 4 screws that invaded the medial wall. However, this does not present a problem because the ligament flavum is a good protector of medially invaded screws. To avoid improper screw insertion, it is essential to have an anatomical understanding of the spinous process and medial lamina wall. Additionally, even though the miniplate screw is selftapping, it does not necessarily mean that the screw will penetrate to the proper insertion point. Creating a screw pathway with a small power drill can make correct insertion of the intralaminar screw easier.

One limitation to this study is that the follow-up period was only 6 months, and posterior neck pain (VAS score) and range of cervical motion were not analyzed. And comparative study should be performed to assess clinical benefits by comparing other cervical laminoplasty methods.

\section{CONCLUSION}

The Box-shape cervical expansive laminoplasty provided maximal canal expansion and demonstrated excellent clinical benefits. This method is easy to perform, provides a rigid construct, and intralaminal screws are placed in the proper position without inducing neurologic deficits.

\section{Conflict of interest}

We certify that this manuscript is a unique submission and that is not being considered for publication by another source or in another medium. The authors have no conflicts of interest to declare. However, the author is the inventor of both the
Miniplate $^{\circledR}$ and Maxpacer ${ }^{\circledR}$, which are the first, plate-type commercial devices for Box-shape cervical expansive laminoplasty.

\section{REFERENCES}

1. Arantes AAJ, Silva GAJ, Malheiros JA, Goncalves FF, Magaldi M, Santiago E, et al: A new expansive two-open-doors laminoplasty for multilevel cervical spondylotic myelopathy: technical report and follow-up results. Arq Neuropsiquiatr 72:49-54, 2014

2. Deutsch H, Mummaneni PV, Rodts GE, Haid RW: Posterior cervical laminoplasty using a new plating system: technical note. J Spinal Disord Tech 17:317-320, 2004

3. Edwards CC, 2nd, Heller JG, Murakami H: Corpectomy versus laminoplasty for multilevel cervical myelopathy: an independent matched-cohort analysis. Spine (Phila Pa 1976) 27:1168-1175, 2002

4. Frank E, Keenen TL: A technique for cervical laminoplasty using mini plates. Br J Neurosurg 8:197-199, 1994

5. Hamburger C, Buttner A, Uhl E: The cross-sectional area of the cervical spinal canal in patients with cervical spondylotic myelopathy. Correlation of preoperative and postoperative area with clinical symptoms. Spine (Phila Pa 1976) 22:1990-1994; discussion 1995, 1997

6. Heller JG, Edwards CC, 2nd, Murakami H, Rodts GE: Laminoplasty versus laminectomy and fusion for multilevel cervical myelopathy: an independent matched cohort analysis. Spine (Phila Pa 1976) 26:1330-1336, 2001

7. Hirabayashi K, Watanabe K, Wakano K, Suzuki N, Satomi K, Ishii Y: Expansive open-door laminoplasty for cervical spinal stenotic myelopathy. Spine (Phila Pa 1976) 8:693-699, 1983

8. Hirabayashi S, Koshizuka Y: New method for measuring area of spinal canal after double-door laminoplasty. J Orthop Sci 4:78-82, 1999

9. Hirabayashi S, Yamada H, Motosuneya T, Watanabe Y, Miura M, Sakai H, et al: Comparison of enlargement of the spinal canal after cervical laminoplasty: open-door type and doubledoor type. Eur Spine J 19:1690-1694, 2010

10. Hukuda S, Ogata M, Mochizuki T, Shichikawa K: Laminectomy versus laminoplasty for cervical myelopathy: brief report. J Bone Joint Surg Br 70:325-326, 1988

11. Itoh T, Tsuji H: Technical improvements and results of laminoplasty for compressive myelopathy in the cervical spine. Spine (Phila Pa 1976) 10:729-736, 1985

12. Kawaguchi Y, Kanamori M, Ishihara H, Ohmori K, Nakamura H, Kimura T: Minimum 10-year followup after en bloc cervical laminoplasty. Clin Orthop Relat Res:129-139, 2003

13. Kawai S, Sunago K, Doi K, Saika M, Taguchi T: Cervical laminoplasty (Hattori's method). Procedure and follow-up results. Spine (Phila Pa 1976) 13:1245-1250, 1988

14. Kim JH, Zhang HY, Park YM; Cervical expansive laminoplasty with $90^{\circ}$ box-shape double door method. Korean J Spine 9(3): 193-196, 2012

15. Machino M, Yukawa Y, Hida T, Ito K, Nakashima H, Kanbara $\mathrm{S}$, et al: Modified double-door laminoplasty in managing multilevel cervical spondylotic myelopathy: surgical outcome in 520 
patients and technique description. J Spinal Disord Tech 26: 135-140, 2013

16. Matsuda Y, Shibata T, Oki S, Kawatani Y, Mashima N, Oishi $\mathrm{H}$ : Outcomes of surgical treatment for cervical myelopathy in patients more than 75 years of age. Spine (Phila Pa 1976) 24: 529-534, 1999

17. Park AE, Heller JG: Cervical laminoplasty: use of a novel titanium plate to maintain canal expansion--surgical technique. J Spinal Disord Tech 17:265-271, 2004

18. Ratliff JK, Cooper PR: Cervical laminoplasty: a critical review. J Neurosurg 98:230-238, 2003

19. Satomi K, Nishu Y, Kohno T, Hirabayashi K: Long-term follow-up studies of open-door expansive laminoplasty for cervical stenotic myelopathy. Spine (Phila Pa 1976) 19:507-510, 1994

20. Tomita K, Kawahara N, Toribatake Y, Heller JG: Expansive midline T-saw laminoplasty (modified spinous process-splitting) for the management of cervical myelopathy. Spine (Phila Pa 1976) 23:32-37, 1998

21. Tsuzuki N, Abe R, Saiki K, Zhongshi L: Extradural tethering effect as one mechanism of radiculopathy complicating posterior decompression of the cervical spinal cord. Spine (Phila Pa 1976) 21:203-211, 1996

22. Uematsu Y, Tokuhashi Y, Matsuzaki H: Radiculopathy after laminoplasty of the cervical spine. Spine (Phila Pa 1976) 23: 2057-2062, 1998 